OPEN ACCESS

Edited by:

Vinood B. Patel,

University of Westminster, UK

Reviewed by:

Ramesh Kandimalla,

Emory University, USA

Marc Dhenain,

Centre National de la Recherche

Scientifique/CEA, France

*Correspondence:

Elizabeth J. Coulthard

elizabeth.coulthard@bristol.ac.uk

Received: 08 November 2015 Accepted: 27 May 2016

Published: 16 June 2016

Citation:

Knight MJ, McCann B, Kauppinen RA and Coulthard EJ (2016) Magnetic Resonance Imaging to Detect Early Molecular and Cellular Changes in Alzheimer's Disease.

Front. Aging Neurosci. 8:139. doi: 10.3389/fnagi.2016.00139

\section{Magnetic Resonance Imaging to Detect Early Molecular and Cellular Changes in Alzheimer's Disease}

\author{
Michael J. Knight ${ }^{1}$, Bryony McCann ${ }^{1}$, Risto A. Kauppinen ${ }^{1,2}$ and Elizabeth J. Coulthard ${ }^{3,4 *}$ \\ ${ }^{1}$ School of Experimental Psychology, University of Bristol, Bristol, UK, ${ }^{2}$ Clinical Research and Imaging Centre, University of \\ Bristol, Bristol, UK, ${ }^{3}$ Research into Memory the Brain and Dementia Group, Institute of Clinical Neuroscience, University of \\ Bristol, Bristol, UK, ${ }^{4}$ North Bristol NHS Trust, Bristol, UK
}

Recent pharmaceutical trials have demonstrated that slowing or reversing pathology in Alzheimer's disease is likely to be possible only in the earliest stages of disease, perhaps even before significant symptoms develop. Pathology in Alzheimer's disease accumulates for well over a decade before symptoms are detected giving a large potential window of opportunity for intervention. It is therefore important that imaging techniques detect subtle changes in brain tissue before significant macroscopic brain atrophy. Current diagnostic techniques often do not permit early diagnosis or are too expensive for routine clinical use. Magnetic Resonance Imaging (MRI) is the most versatile, affordable, and powerful imaging modality currently available, being able to deliver detailed analyses of anatomy, tissue volumes, and tissue state. In this mini-review, we consider how MRI might detect patients at risk of future dementia in the early stages of pathological change when symptoms are mild. We consider the contributions made by the various modalities of MRI (structural, diffusion, perfusion, relaxometry) in identifying not just atrophy (a late-stage $\mathrm{AD}$ symptom) but more subtle changes reflective of early dementia pathology. The sensitivity of MRI not just to gross anatomy but to the underlying "health" at the cellular (and even molecular) scales, makes it very well suited to this task.

Keywords: Alzheimer's, magnetic resonance imaging, shape analysis, relaxometry, diffusion tensor imaging

\section{INTRODUCTION}

Alzheimer's disease (AD) is the most prevalent form of dementia (Jorm and Jolley, 1998), with Mild Cognitive Impairment (MCI) often indicating a pre-AD phase (Albert et al., 2011), but even at this point, brain pathology has been accumulating for many years (Jack et al., 2013). Hallmark pathological changes in Alzheimer's disease (AD) are amyloid plaques and neurofibrillary tangles containing hyperphosphorylated tau (Perl, 2010) with associated cerebral amyloid angiopathy in over $80 \%$ of cases (Ellis et al., 1996).

Early diagnosis of dementia is becoming critical as emerging treatments may delay progression of disease only in the earliest stages (Liu-Seifert et al., 2015), before most patients are diagnosed. The annualized conversion rate from MCI to AD is around 10\% (Ward et al., 2013), but many patients with symptoms of MCI will not develop dementia (even when there is some biomarker evidence of AD, Jack et al., 2016) and some will develop non-AD dementia. So symptoms alone cannot accurately predict those who have early stage $\mathrm{AD}$. Current routine clinical tests include: 
1. Neuropsychology reveals a pattern of deficits consistent with $\mathrm{AD}$ in the early stages, but changes are non-specific and an individual's baseline can be hard to ascertain;

2. Structural imaging Computed Tomography or MRI can identify groups with $\mathrm{MCI}$ likely to progress to $\mathrm{AD}$ (Risacher et al., 2009), but current implementations do not classify an individual with sufficient accuracy. Although generally well tolerated, MRI can be limited by symptoms of claustrophobia and presence of metal implants.

3. Positron Emission Tomography (PET) and Single Photon Emission Computed Tomography (O'Brien et al., 2014; Archer et al., 2015; Weiner et al., 2015) Amyloid PET can differentiate $\mathrm{AD}$ from healthy controls with over $95 \%$ accuracy (albeit with substantial false positive rate) and also identifies most people with MCI likely to develop AD (Vandenberghe et al., 2013). Although not in routine clinical use, there are also PET ligands that bind to phosphorylated-tau (FDDNP molecule (Small et al., 2006) and ${ }^{18} \mathrm{~F}$ AV1451) that have recently been shown to track progressive tau accumulation in aging and Alzheimer's disease Schöll et al. The expense of these tests is prohibitive in most centers.

4. Lumbar puncture Low amyloid and raised tau in cerebrospinal fluid (CSF) predict AD with 95\% sensitivity and $87 \%$ specificity after $4-6$ years' follow up (Hansson et al., 2006), but lumbar puncture is an invasive test.

MRI is widely available and patients are routinely imaged in diagnostic work up. Therefore, we predict that updated application of MRI will become increasingly important for accurate dementia diagnosis.

\section{FUNDAMENTAL PRINCIPLES OF MRI}

MRI exploits magnetic properties of atomic nuclei with the quantum mechanical property of spin angular momentum, commonly known as "the spin." Hydrogen $\left({ }^{1} \mathrm{H}\right)$ is an abundant atom in vivo with a spin. As water molecules have two ${ }^{1} \mathrm{Hs}$ and our body is $\sim 70 \%$ water, ${ }^{1} \mathrm{H}$ is an excellent reporter for MRI (sodium $={ }^{23} \mathrm{Na}$ is the other inherent nucleus used for MRI of living objects, not covered here). Thus, MR image detects water in vivo in a spatially-specific manner where MR signal is weighted to a given biophysical property of ${ }^{1} \mathrm{H}$ according to the data acquisition procedure.

Clinical MRI of human brain uses scanners with magnetic field strength typically ranging from 1 Tesla (T) to 3T; in research settings magnets up to $9.4 \mathrm{~T}$ (ultra-high field systems operate $\geq 7 \mathrm{~T}$ ) are used for humans. The strong magnet produces "net magnetisation" of ${ }^{1} \mathrm{H}$ nuclei that results from "spin excess" in alignment in the magnetic field. The amount of net magnetisation scales up with the magnetic field strength so that the signal-to-noise ratio (SNR) in MR images increases roughly linearly with the field. So, there is a clear imperative toward higher magnetic fields as higher SNR can yield higher spatial resolution, improved temporal resolution in functional imaging, or improved access to microstructural information in diffusion imaging (at a constant spatial resolution).
Signal intensity in the MR image is chosen according to dynamic properties of the ${ }^{1} \mathrm{H}$ nuclei, such as rotational and translational motions, that are weighted according to the MR data acquisition parameters. Rotational motion of nuclei is probed through MR relaxation, which is described by two time constants: the longitudinal relaxation time or $\mathrm{T}_{1}$ and the transverse relaxation time or $\mathrm{T}_{2} . \mathrm{T}_{1}$ and $\mathrm{T}_{2}$ are commonly exploited for structural MRI at macroscopic scale, also known as volumetry. It should be stressed that both quantitative $\mathrm{T}_{1}$ (Barazany and Assaf, 2012) and $\mathrm{T}_{2}$ (MacKay et al., 1994) can also provide data indirectly from tissue microstructure.

\section{Morphometry}

In this section we will cover volumetry (which we define as volume analysis of macroscopic brain structures), cortical thickness and shape analyses [Voxel Based Morphometry or parcellation not reviewed (See Whitwell et al., 2012 for information; Yang et al., 2012)].

The volume of a tissue or subcortical structure in the brain is reflective of the number of neurons, dendritic processes or synapses (Schuff et al., 2009; Jack, 2012). Quantitation of volumes is therefore sensitive to various diseases and their progression. MRI is an excellent modality to quantify brain and subcortical volumes and is widely used in assessment of suspected MCI or AD (Jack et al., 2012; Weiner et al., 2015). MR volumetry generally uses $3 \mathrm{D} \mathrm{T}_{1}$-weighted data sets, which can be acquired at a $1 \mathrm{~mm}$ isotropic resolution in around $5 \mathrm{~min}$. Volumetric analysis based on such data can readily be automated, for which various fast and robust software packages exist (Dale et al., 1999; TzourioMazoyer et al., 2002; Fischl et al., 2004; Jack, 2012) and this would enhance clinical practice if implemented in the near future.

Cortical thickness estimates (Li et al., 2015; Redolfi et al., 2015) are straightforward from $3 \mathrm{D} \mathrm{T}_{1}$-weighted images. It should be noted that what is said about $3 \mathrm{D} \mathrm{T}_{1}$-weighted images apply to scans acquired at clinical field strengths. At ultra-high fields $\mathrm{T}_{1}$ becomes longer which has to be accounted for in setting data acquisition parameters. The same brain region of two individuals may atrophy by the same amount, but localized to different particular subregions, yielding the same volume (and volume loss) but different symptoms for the afflicted individuals; shape analysis seeks to address this.

\section{Functional MRI}

Functional MRI (fMRI) most commonly probes haemodynamic response, resulting from local decline in the ratio of deoxyhaemoglobin-to-oxyhaemoglobin and increase in blood volume elicited in response to "brain activation." The so-called Blood Oxygenation Level Dependent (BOLD) signal localizes haemodynamic response to brain activation, the BOLD effect influencing the transverse relaxation rates $T_{2}$ and $T_{2}^{*}$. Reduction of local magnetic gradients and increased blood volume prolong parenchymal $\mathrm{T}_{2}\left({ }^{*}\right)$, which is recorded as a positive BOLD signal by means of $\mathrm{T}_{2}(*)$-weighted MRI.

Haemodynamic responses due to experimental external events result in task-activated BOLD fMRI from which inferences have been made with regard to cognitive function. Fluctuations in BOLD without an external trigger, the so-called resting state 
fMRI, allows indirect inference about intrinsic brain connectivity and this may change as a result of neurodegenerative disease and is discussed below.

\section{Diffusion Tensor Imaging}

Diffusion tensor imaging (DTI) seeks to image the translational (thermal) motion of water, which is a tensor field (different in different directions and different at every voxel of the image) due to microstructural barriers to diffusion (e.g., cells/subcellular structures) constraining the motion of water differently along different directions (Basser and Jones, 2002). The translational motion of water is probed by sensitizing the MR signal to "diffusion" by means of magnetic field gradient-based approaches (see Figure 1 for an example). Because of this DTI can inform about the tissue microstructure at subvoxel resolution-it is the cellular and subcellular architecture which constrains the motion of water in vivo. Whilst DTI contains a wealth of information from water diffusion in vivo, analysis often focuses on the extraction of the mean diffusivity (MD) and fractional anisotropy (FA), referred to as DTI metrics below, as well as axial and radial diffusivity (Stebbins and Murphy, 2009; Amlien and Fjell, 2014; Zhang et al., 2014). The MD refers to the average rate of diffusion along the three axes of the diffusion tensor and is sensitive to water content and overall tortuosity (level of "constraint" of diffusion) of the environment. FA parameterises the extent to which diffusion is different along the three axes of the diffusion tensor, taking extreme values of zero when diffusion is the same in all directions (as in CSF) and unity when constrained entirely along a single direction (such as along a fiber tract). DTI can be used to estimate axonal density and diameter in white matter as indices of white matter integrity (Madden et al., 2012).

\section{MR Spectroscopy}

Magnetic resonance spectroscopy (MRS) seeks to observe a spectrum of resonance lines, each deriving from a unique spin

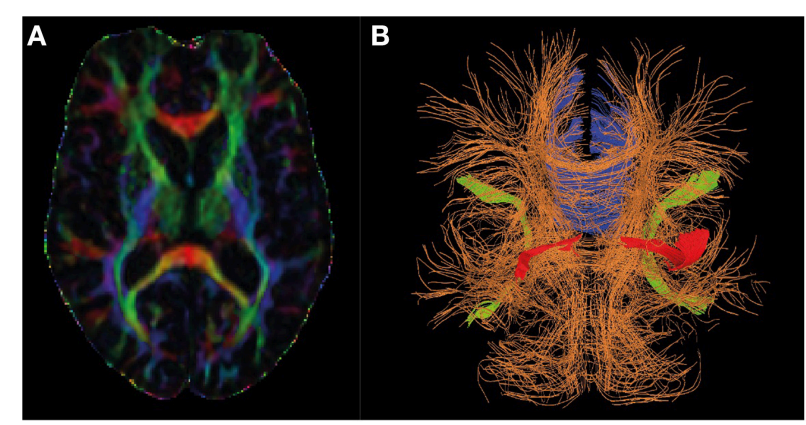

FIGURE 1 | Diffusion tensor MRI in Alzheimer's research. Panel (A) shows the directional information encoded by diffusion tensor imaging by color (red: left-right, green: anterior-posterior, blue: head-foot) and fractional anisotropy (high intensity implies high fractional anisotropy). Panel (B) shows how the directional information may be represented in a deterministic tractography analysis, and shows the regions consistently identified and changing in AD (Blue: Corpus callosum, red: uncinate fasciculus, green: superior lateral fasciculus). state transition frequency. Although, there is much overlap of lines in the magnetic resonance spectrum of an in vivo system, which contains many molecules each with many spins, there are still enough well resolved resonances deriving from unique metabolites for it to be a very powerful method. A unique feature of ${ }^{1} \mathrm{H}$ MRS is that it reveals cell-specific metabolite biomarkers, such as N-acetyl asparate (NAA) and myo-inositol (Amlien and Fjell, 2014). The intensities or integrals of spectral lines are directly informative of metabolite concentrations. MRS can be performed with spatial specificity, recording a spectrum from a voxel of choice within the brain $(\mathrm{Oz}$ et al., 2014).

\section{Relaxometry}

Magnetic resonance relaxometry is the imaging of relaxation parameters such as $T_{1}, T_{2}, T_{2}^{*}$, and $T_{1 \rho}$, describing various aspects of the re-equilibration of the spin system after perturbation by radiofrequency pulses. Like diffusion parameters, they essentially describe the status of a tissue. Typically they take higher values when a tissue is "unhealthy" due to oedema (more motile water present) or when cells have been broken down, reducing dephasing of magnetisation, thus prolonging signal lifetimes quantified by $\mathrm{T}_{2}$ and $\mathrm{T}_{2}^{*}$, and making water by and large more motile, which increases all relaxation parameters.

\section{Brain Perfusion}

Brain perfusion, which is driven by cerebral blood flow, can be detected by arterial spin labeling (ASL) MRI. In ASL MRI the arterial blood entering the brain is magnetically labeled either by radio frequency (RF)-field or RF-inversion pulse. The signal decline between the non-labeled ("control") and labeled ASL images is proportional to the tissue perfusion and the signal difference can be converted with appropriate procedures into absolute units of blood perfusing a unit volume of tissue per minute (Alsop et al., 2015).

\section{BRAIN ATROPHY IN AD AND MCI}

A slow decrease in total brain volume is part of physiological aging (Peters, 2006). Both white matter (WM) and gray matter (GM) decline in volume during normal aging (Sullivan et al., 1995; Salat et al., 1999; Peters, 2006; Scahill and Fox, 2007) with gray matter atrophy undergoing global atrophy accelerated in insula, superior parietal gyri, central sulci, and cingulate sulci and relative sparing in amygdala, hippocampi, and entorhinal cortex. In contrast, global white matter does not decline, but there are islands of accelerated decline particularly of white matter areas to frontal lobes and thalamus (Good et al., 2001). An increased rate of atrophy is predictive of AD (Jack, 2012), though also of other forms of dementia (Chan et al., 2001). An abnormal ratio of GM to cerebrospinal fluid (CSF) is also suggestive of a disease processes (Sullivan et al., 1995; Salat et al., 1999).

\section{Hippocampal Atrophy in AD and $\mathrm{MCl}$}

Atrophy rates are different for different regions and tissues. In particular, the hippocampus often suffers particularly severe 
atrophy in AD (Jack, 2012), and often (though not always) before the outward display of cognitive symptoms. Volumetric analysis of the whole $\mathrm{HC}$ has been shown to be an effective biomarker for demonstrating short-term clinical decline in AD (Landau et al., 2010; Ewers et al., 2012; Lehmann et al., 2013; Jack et al., 2015) and also shows relative success at predicting conversion from MCI to AD (Schuff et al., 2012; Liu et al., 2013). Rate of atrophy has consistently performed well in comparison to other biomarkers and cognitive indices (Holland et al., 2012; Leung et al., 2013; Jack et al., 2015).

However, the $\mathrm{HC}$ is a complex structure, composed of several subfields (Figure 2), distinct in terms of cellular content and connections with other brain regions (Duvernoy, 2005). Autopsy data show that these are differentially vulnerable to $\mathrm{AD}$ pathology (Braak and Braak, 1991; Jack et al., 2002; Silbert et al., 2003; Fearing et al., 2007; Zhang et al., 2015).

An increasing body of recent research indicates that the quantitation of individual subfield volumes has superior sensitivity and specificity in detecting and distinguishing $\mathrm{AD}$ and MCI, as well as other dementias (La Joie et al., 2013; Li et al., 2013; Maruszak and Thuret, 2014; Perrotin et al., 2015). An emerging picture is that the CA1 and subiculum subfields have the highest diagnostic power in detecting early $\mathrm{AD}$ (de Flores et al., 2015).

There is ongoing research to automate the labeling of hippocampal subfields in MR images (Yushkevich et al., 2015).

\section{Beyond the Hippocampus}

Beyond the HC, temporal and parietal volumes can identify healthy individuals who are at risk of future memory decline (Chiang et al., 2011). Other areas including subfields within the thalamus-a connectivity hub for the neocortex-are abnormal

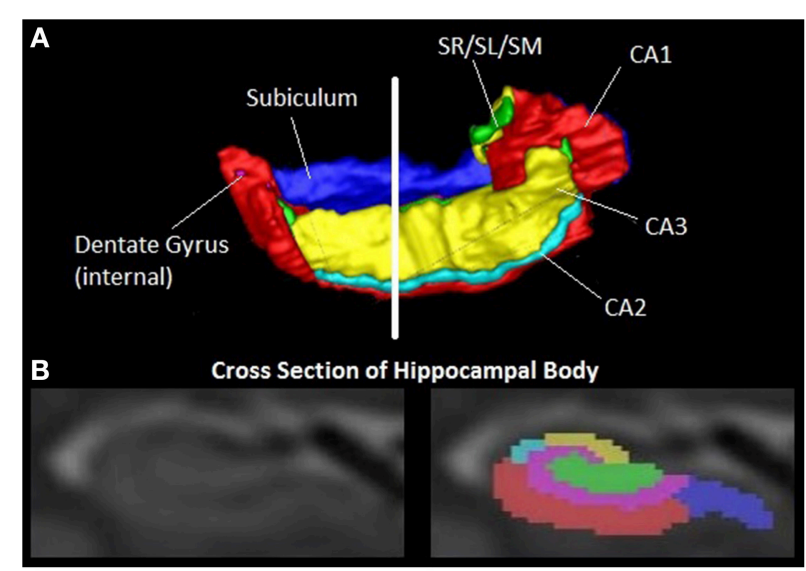

FIGURE 2 | The human hippocampus. Image shows a 3D representation of the right hippocampus with six subfields and a coronal MR image of the hippocampal body with corresponding subfields. Segmentation as described in (Wood et al., 2015). Red $=$ CA1, Light blue $=\mathrm{CA} 2$, yellow $=\mathrm{CA} 3$, blue $=$ subiculum, pink $=$ dentate gyrus, green $=$ Stratum radiatum $/$ stratum lacunosum/ stratum moleculare (SR/SL/SM). in established AD (Braak and Braak, 1991). A fascinating area to consider for the future is how brain network disruption including distributed brain areas might actually precede and even propagate $\mathrm{AD}$ pathology (Kapogiannis and Mattson, 2011; Sotiropoulos et al., 2013). Thus, metabolic and network biomarkers such as fMRI and DTI may become important. However, currently medial temporal and parietal regions have been shown to be individual regions most susceptible to changes of early AD (Heckemann et al., 2011).

The medial temporal area Entorhinal cortex (EC), in particular, is recognized as a region severely affected by $\mathrm{AD}$ pathology and is reported to be the most heavily damaged cortex in AD (Van Hoesen et al., 1991). EC atrophy is predicted to occur prior to hippocampal damage and is one of the earliest signs of disease manifestation. The rate of atrophy in the EC correlates with severity of cognitive symptoms ( $\mathrm{Li}$ et al., 2012) and is considered predictive of conversion from MCI to AD (Devanand et al., 2007).

Furthermore, $\mathrm{AD}$ patients display cortical thinning in bilateral, frontal, parietal, and occipital lobes compared to controls and thinner cortex in parts of the bilateral parietal and precuneus region compared to frontotemporal dementia (Du et al., 2007). A negative correlation between cognitive performance and cortical thickness was also reported in these regions (Du et al., 2007), indicating that cortical thickness in these regions is a marker of disease severity.

\section{BEYOND VOLUME: ANALYSIS OF SHAPE}

The patterns of loss of cortical thickness from MRI agree with those seen in autopsies and appear in early phase of AD in the inferior temporal lobe cortex (Marshall et al., 2014), followed by peri-ventricular structures prior to a more widespread cortical thinning. Salat et al. reported that cortical thinning in $\mathrm{AD}$ is associated with decrease in contrast-to-noise-ratio (CNR) between gray and white matter in $\mathrm{T}_{1}$ images (Salat et al., 2011). The decrease in CNR is thought to result from microstructural changes in brain tissue, which are likely to precede loss of tissue volume and could be earlier indication of imminent pathology (Westlye et al., 2009; Callaghan et al., 2014).

Both local displacements and global shape alterations in the hippocampus have been shown to distinguish AD from MCI (Wang et al., 2003; Thompson et al., 2004; Ceyhan et al., 2011), and identify $\mathrm{MCI}$ to $\mathrm{AD}$ conversion rates with $80 \%$ accuracy (Costafreda et al., 2011). Involvement of the CA1 subfield has been consistently reported in the latter studies, particularly in the right hemisphere in agreement with detailed volumetric analysis and autopsy findings.

\section{INCREASED DIFFUSIVITY AND DECREASED FRACTIONAL ANISOTROPY ARE THE HALLMARKS OF MCI AND AD}

The general picture from the use of MD and FA as diffusion metrics is that MD is increased whereas FA is decreased in 
$\mathrm{AD}$ and $\mathrm{MCI}$ patients relative to controls. In a meta-analysis of AD and MCI studies conducted up to 2010 (Sexton et al., 2011), the largest MD effects were found to be localized to the $\mathrm{HC}$, temporal and parietal regions. The largest FA decreases relative to controls have generally been found in the uncinate fasciculus, superior lateral fasciculus and corpus callosum. More recent work (Palesi et al., 2012; Hong et al., 2013; Jacobs et al., 2013) has continued to reinforce these findings. It has also been reported in recent studies that axial and radial diffusivity show widespread increases in both MCI and $\mathrm{AD}$, and that these measures are more sensitive to dementia and cognitive impairment than FA (Shu et al., 2011; Nir et al., 2013). DTI has been shown to have superior patient/non-patient classification capability relative to volumetric analysis alone (Santillo et al., 2013) and in combination therewith (McMillan et al., 2014).

\section{DTI METRICS AND CEREBROSPINAL FLUID (CSF) BIOMARKERS IN AD AND MCI}

There has been work recently to relate levels of known $\mathrm{AD}$ CSF biomarkers Tau and Amyloid. Although a consensus has yet to be reached, there is an emerging picture that DTI is a powerful complement to the use of CSF biomarkers (Clerx et al., 2012).

CSF biomarkers have been variously related to increased hippocampal MD in AD (Bendlin et al., 2012; Douaud et al., 2013) and white matter FA in MCI (Selnes et al., 2013), with the general conclusion that DTI measures are superior predictors of $\mathrm{AD}$ than CSF biomarkers, and the use of DTI and CSF biomarker quantitation in concert is superior again.

\section{RELAXOMETRY}

A recent study quantifying $T_{1 \rho}$ in the medial temporal lobe (MTL) showed increased $\mathrm{T}_{1 \rho}$ in MTL WM and GM in AD (Haris et al., 2011) and that its measurement, like DTI, surpassed the sensitivity of CSF biomarkers Tau and A $\beta 42$ in diagnosing $A D$, though CSF biomarkers showed better specificity (Haris et al., 2015).

\section{FUNCTIONAL CONNECTIVITY (OR RESTING-STATE MRI)}

There has been increasing interest in recent years in restingstate functional connectivity, where MRI is monitored by BOLD contrast. A large literature now exists on resting state fMRI applications in dementia (Zhou and Seeley, 2014). Whilst the results have not yet fully converged, recent reviews of applications in AD (Sheline and Raichle, 2013; Krajcovicova et al., 2014) note consistent observations of alterations to the default mode network, though many brain networks are variously implicated. Interestingly, the relationship between functional connectivity, brain volume and cognitive ability differs during lifespan with, for example, cortico-striatal functional connectivity being related to change in recall of episodic memory in older adults more than younger people (Fjell et al., 2015).

\section{PERFUSION IMAGING AND AMYLOID RELATED VASCULAR CHANGES}

An emerging picture in $\mathrm{AD}$ research is the role of cerebral perfusion, with vascular changes occurring early in disease progression (Mazza et al., 2011). In particular, global and regional cerebral hypoperfusion are associated with the disease, though debate continues as to whether this is a cause or effect (de la Torre, 2000). Either way, the observation that $\mathrm{AD}$ is thereby linked to modifiable vascular risk factors has attracted considerable attention. Hypoperfusion as measured by ASL has been consistently observed in the posterior cingulate, precuneus, inferior parietal, and lateral prefontal cortices (Alsop et al., 2010; Wolk and Detre, 2012; Wierenga et al., 2014). ASL findings compare well to FDG-PET (Musiek et al., 2012), with recent data also suggesting the capacity of ASL to add to diagnostic power, with distinct patterns of perfusion in different dementias (Binnewijzend et al., 2014).

As well as atherosclerotic changes in people with $\mathrm{AD}$, blood vessels can be affected by cerebral amyloid angiopathy or damage from amyloid-modifying therapies (known as Amyloid Related Imaging Abnormalities-ARIA). Such changes include vasogenic oedema (visualized on $\mathrm{T}_{2}$ weight Fluid Attenuation Inversion Recovery Sequences) and microhaemorrhages (visible on $\mathrm{T}_{2}^{*}$ sequences such as Gradient Echo) (Sperling et al., 2011).

\section{SPECTROSCOPY}

In the large literature on the use of ${ }^{1} \mathrm{H}$ MRS in dementia, consistent findings in AD include significantly reduced NAA, the neuron-specific MRS biomarker, in the posterior cingulate and bilateral hippocampus (Murray et al., 2014; Wang et al., 2015). Similar to NAA, glutamate has been shown to be decreased in these brain structures (Alsop et al., 2010). The glial metabolite, myo-inositol, is increased in the posterior cingulate (PC) and parietal GM (Wang et al., 2015; Murray et al., 2014). NAA concentration in the posterior cingulate of MCI patients has been reported to be intermediate between controls and $\mathrm{AD}$ patients. Applications of MRS to MCI have found broadly similar results, and additionally that choline was reduced in the hippocampus but Choline/Creatine ratio raised in the PC. Myoinositol/creatine ratio was also raised in the hippocampus while NAA was reduced in paratrigonal WM, hippocampus and PC (Kantarci, 2013; Tumati et al., 2013; Zhang et al., 2015).

\section{SUMMARY/CONCLUSION}

Early detection and treatment of dementia is conceivable in the coming generation and remains one of the most pressing current 
challenges for healthcare research. The contributions from MRI are potentially substantial with, for example, automated hippocampal subfield volumetrics and DTI already having significant support for clinical application and relaxometry, perfusion imaging and MRS being active areas of research that could lead to clinical applicability. Future research directions should concentrate on optimum combination of available test for early accurate cost effective dementia diagnosis.

\section{REFERENCES}

Albert, M. S., DeKosky, S. T., Dickson, D., Dubois, B., Feldman, H. H., Fox, N. C., et al. (2011). The diagnosis of mild cognitive impairment due to Alzheimer's disease: recommendations from the National Institute on Aging-Alzheimer's Association workgroups on diagnostic guidelines for Alzheimer's disease. Alzheimers Dement. 7, 270-279. doi: 10.1016/j.jalz.2011. 03.008

Alsop, D. C., Dai, W., Grossman, M., and Detre, J. A. (2010). Arterial spin labeling blood flow MRI: its role in the early characterization of Alzheimer's disease. J. Alzheimers Dis. 20, 871-880. doi: 10.3233/JAD-2010-091699

Alsop, D. C., Detre, J. A., Golay, X., Gunther, M., Hendrikse, J., HernandezGarcia, L., et al. (2015). Recommended implementation of arterial spin-labeled perfusion MRI for clinical applications: a consensus of the ISMRM perfusion study group and the European consortium for ASL in dementia. Mag. Reson. Med. 73, 102-116. doi: 10.1002/mrm.25197

Amlien, I. K., and Fjell, A. M. (2014). Diffusion tensor imaging of white matter degeneration in Alzheimer's disease and mild cognitive impairment. Neuroscience 276, 206-215. doi: 10.1016/j.neuroscience.2014.02.017

Archer, H. A., Smailagic, N., John, C., Holmes, R. B., Takwoingi, Y., Coulthard, E. J., et al. (2015). Regional Cerebral Blood Flow Single Photon Emission Computed Tomography for detection of Frontotemporal dementia in people with suspected dementia. Cochrane Database of Syst. Rev, CD010896. doi: 10.1002/14651858.CD010896.pub2

Barazany, D., and Assaf, Y. (2012). Visualization of cortical lamination patterns with magnetic resonance imaging. Cereb. Cortex 22, 2016-2023. doi: $10.1093 /$ cercor/bhr277

Basser, P. J., and Jones, D. K. (2002). Diffusion-tensor MRI: theory, experimental design and data analysis - a technical review. NMR Biomed. 15, 456-467. doi: $10.1002 / \mathrm{nbm} .783$

Bendlin, B. B., Carlsson, C. M., Johnson, S. C., Zetterberg, H., Blennow, K., Willette, A. A., et al. (2012). CSF T-Tau/Abeta42 predicts white matter microstructure in healthy adults at risk for Alzheimer's disease. PLoS ONE 7:e37720. doi: 10.1371/journal.pone.0037720

Binnewijzend, M. A., Kuijer, J. P., van der Flier, W. M., Benedictus, M. R., Moller, C. M., Pijnenburg, Y. A., et al. (2014). Distinct perfusion patterns in Alzheimer's disease, frontotemporal dementia and dementia with Lewy bodies. Eur. Radiol. 24, 2326-2333. doi: 10.1007/s00330-014-3172-3

Braak, H., and Braak, E. (1991). Neuropathological stageing of Alzheimer's relatedchanges. Acta Neuropathol. 82, 239-259. doi: 10.1007/BF00308809

Callaghan, M. F., Freund, P., Draganski, B., Anderson, E., Cappelletti, M., Chowdhury, R., et al. (2014). Widespread age-related differences in the human brain microstructure revealed by quantitative magnetic resonance imaging. Neurobiol. Aging 35, 1862-1872. doi: 10.1016/j.neurobiolaging.2014.02.008

Ceyhan, E., Beg, M. F., Cerito, C., Wang, L., Morris, J. C., Csernansky, J. G., et al. (2011). Quantization and analysis of hippocampal morphometric changes due to dementia of Alzheimer type using metric distances based on large deformation diffeomorphic metric mapping. Comput. Med. Imaging Graph. 35, 275-293. doi: 10.1016/j.compmedimag.2011.01.005

Chan, D., Fox, N. C., Scahill, R. I., Crum, W. R., Whitwell, J. L., Leschziner, G., et al. (2001). Patterns of temporal lobe atrophy in semantic dementia and Alzheimer's disease. Ann. Neurol. 49, 433-442. doi: 10.1002/ana.92

Chiang, G. C., Insel, P. S., Tosun, D., Schuff, N., Truran-Sacrey, D., Raptentsetsang, S., et al. (2011). Identifying cognitively healthy elderly individuals with

\section{AUTHOR CONTRIBUTIONS}

All authors contributed to the writing and editing of the Manuscript. MK and BW produced the figures.

\section{ACKNOWLEDGMENTS}

Our research is supported by grants from Alzheimer's Research UK and BRACE Charity. MJK is supported by an Elizabeth Blackwell Institute early career fellowship 770-7.

subsequent memory decline by using automated MR temporoparietal volumes. Radiology 259, 844-851. doi: 10.1148/radiol.11101637

Clerx, L., Visser, P. J., Verhey, F., and Aalten, P. (2012). New MRI markers for Alzheimer's disease: a meta-analysis of diffusion tensor imaging and a comparison with medial temporal lobe measurements. J. Alzheimers Dis. 29, 405-429. doi: 10.3233/JAD-2011-110797

Costafreda, S. G., Dinov, I. D., Tu, Z., Shi, Y., Liu, C.-Y., Kloszewska, I., et al. (2011). Automated hippocampal shape analysis predicts the onset of dementia in mild cognitive impairment. Neuroimage 56, 212-219. doi: 10.1016/j.neuroimage.2011.01.050

Dale, A. M., Fischl, B., and Sereno, M. I. (1999). Cortical surface-based analysis: Segmentation, I., and surface reconstruction. Neuroimage 9, 179-194. doi: 10.1006/nimg.1998.0395

de Flores, R., La Joie, R., and Chetelat, G. (2015). Structural imaging of hippocampal subfields in healthy aging and Alzheimer's disease. Neuroscience. 309, 29-50. doi: 10.1016/j.neuroscience.2015.08.033

de la Torre J. C. (2000). Critically attained threshold of cerebral hypoperfusion: can it cause Alzheimer's disease? Ann. N.Y. Acad. Sci. 903, 424-436. doi: 10.1111/j.1749-6632.2000.tb06394.x

Devanand, D., Pradhaban, G., Liu, X., Khandji, A., De Santi, S., Segal, S., et al. (2007). Hippocampal and entorhinal atrophy in mild cognitive impairment Prediction of Alzheimer disease. Neurology 68, 828-836. doi: 10.1212/01.wnl.0000256697.20968.d7

Douaud, G., Menke, R. A., Gass, A., Monsch, A. U., Rao, A., Whitcher, B., et al. (2013). Brain microstructure reveals early abnormalities more than two years prior to clinical progression from mild cognitive impairment to Alzheimer's disease. J. Neurosci. 33, 2147-2155. doi: 10.1523/JNEUROSCI.443 7-12.2013

Du, A.-T., Schuff, N., Kramer, J. H., Rosen, H. J., Gorno-Tempini, M. L., Rankin, K., et al. (2007). Different regional patterns of cortical thinning in Alzheimer's disease and frontotemporal dementia. Brain 130, 1159-1166. doi: $10.1093 /$ brain/awm016

Duvernoy, H. M. (2005). The Human Hippocampus: Functional Anatomy, Vascularization and Serial Sections with MRI. Berlin; Heidelberg: SpringerVerlag.

Ellis, R. J., Olichney, J. M., Thal, L. J., Mirra, S. S., Morris, J. C., Beekly, D., et al. (1996). Cerebral amyloid angiopathy in the brains of patients with Alzheimer's disease: the CERAD experience, part XV. Neurology 46, 1592-1596. doi: 10.1212/WNL.46.6.1592

Ewers, M., Walsh, C., Trojanowski, J. Q., Shaw, L. M., Petersen, R. C., Jack, C. R., et al. (2012). Prediction of conversion from mild cognitive impairment to Alzheimer's disease dementia based upon biomarkers and neuropsychological test performance. Neurobiol. Aging 33, 1203-1214. doi: 10.1016/j.neurobiolaging.2010.10.019

Fearing, M. A., Bigler, E. D., Norton, M., Tschanz, J. A., Hulette, C., Leslie, C., et al. (2007). Autopsy-confirmed Alzheimer's disease versus clinically diagnosed Alzheimer's disease in the Cache County Study on Memory and Aging: a comparison of quantitative MRI and neuropsychological findings. J. Clin. Exp. Neuropsychol. 29, 553-560. doi: 10.1080/13803390600826579

Fischl, B., van der Kouwe, A., Destrieux, C., Halgren, E., Ségonne, F., Salat, D. H., et al. (2004). Automatically parcellating the human cerebral cortex. Cereb. Cortex 14, 11-22. doi: 10.1093/cercor/bhg087

Fjell, A. M., Sneve, M. H., Storsve, A. B., Grydeland, H., Yendiki, A., and Walhovd, K. B. (2015). Brain events underlying episodic memory changes in aging: 
a longitudinal investigation of structural and functional connectivity. Cereb. Cortex. 1-15. doi: 10.1093/cercor/bhv102

Good, C. D., Johnsrude, I. S., Ashburner, J., Henson, R. N., Friston, K. J., and Frackowiak, R. S. (2001). A voxel-based morphometric study of ageing in 465 normal adult human brains. Neuroimage 14, 21-36. doi: 10.1006/nimg.2001.0786

Hansson, O., Zetterberg, H., Buchhave, P., Londos, E., Blennow, K., and Minthon, L. (2006). Association between CSF biomarkers and incipient Alzheimer's disease in patients with mild cognitive impairment: a follow-up study. Lancet Neurol. 5, 228-234. doi: 10.1016/S1474-4422(06)70355-6

Haris, M., Singh, A., Cai, K., McArdle, E., Fenty, M., Davatzikos, C., et al. (2011). T(1rho) MRI in Alzheimer's disease: detection of pathological changes in medial temporal lobe. J. Neuroimaging 21, e86-e90. doi: 10.1111/j.15526569.2010.00467.x

Haris, M., Yadav, S. K., Rizwan, A., Singh, A., Cai, K., Kaura, D., et al. (2015). T1rho MRI and CSF biomarkers in diagnosis of Alzheimer's disease. Neuroimage Clin. 7, 598-604. doi: 10.1016/j.nicl.2015.02.016

Heckemann, R. A., Keihaninejad, S., Aljabar, P., Gray, K. R., Nielsen, C., Rueckert, D., et al. (2011). Automatic morphometry in Alzheimer's disease and mild cognitive impairment. Neuroimage 56, 2024-2037. doi: 10.1016/j.neuroimage.2011.03.014

Holland, D., Desikan, R. S., Dale, A. M., McEvoy, L. K., and Alzheimer's Disease Neuroimaging Initiative (2012). Rates of decline in Alzheimer disease decrease with age. PLoS ONE 7:e42325. doi: 10.1371/journal.pone.0042325

Hong, Y. J., Yoon, B., Lim, S. C., Shim, Y. S., Kim, J. Y., Ahn, K. J., et al. (2013). Microstructural changes in the hippocampus and posterior cingulate in mild cognitive impairment and Alzheimer's disease: a diffusion tensor imaging study. Neurol. Sci. 34, 1215-1221. doi: 10.1007/s10072-012-1225-4

Jack, C., Dickson, D. W., Parisi, J. E., Xu, Y., Cha, R., O’brien, P., et al. (2002). Antemortem MRI findings correlate with hippocampal neuropathology in typical aging and dementia. Neurology 58, 750-757. doi: 10.1212/WNL.58.5.750

Jack, C. R. Jr. (2012). Alzheimer disease: new concepts on its neurobiology and the clinical role imaging will play. Radiology 263, 344-361. doi: 10.1148/radiol.12110433

Jack, C. R., Barnes, J., Bernstein, M. A., Borowski, B. J., Brewer, J., Clegg, S., et al. (2015). Magnetic resonance imaging in Alzheimer's Disease Neuroimaging Initiative 2. Alzheimer's Dement. 11, 740-756. doi: 10.1016/j.jalz.2015.05.002

Jack, C. R. Jr., Knopman, D. S., Chetelat, G., Dickson, D., Fagan, A. M., Frisoni, G. B., et al. (2016). Suspected non-Alzheimer disease pathophysiology [mdash] concept and controversy. Nat. Rev. Neurol. 12, 117-124. doi: 10.1038/nrneurol.2015.251

Jack, C. R. Jr., Knopman, D. S., Jagust, W. J., Petersen, R. C., Weiner, M. W., Aisen, P.S., et al. (2013). Tracking pathophysiological processes in Alzheimer's disease: an updated hypothetical model of dynamic biomarkers. Lancet Neurol. 12, 207-216. doi: 10.1016/S1474-4422(12)70291-0

Jack, C. R., Knopman, D. S., Weigand, S. D., Wiste, H. J., Vemuri, P., Lowe, V., et al. (2012). An operational approach to National Institute on Aging-Alzheimer's Association criteria for preclinical Alzheimer disease. Ann. Neurol. 71, 765-775. doi: 10.1002/ana.22628

Jacobs, H. I., van Boxtel, M. P., Gronenschild, E. H., Uylings, H. B., Jolles, J., and Verhey, F. R. (2013). Decreased gray matter diffusivity: a potential early Alzheimer's disease biomarker? Alzheimers Dement. 9, 93-97. doi: 10.1016/j.jalz.2011.11.004

Jorm, A. F., and Jolley, D. (1998). The incidence of dementia: a meta-analysis. Neurology 51, 728-733. doi: 10.1212/WNL.51.3.728

Kantarci, K. (2013). Proton MRS in mild cognitive impairment. J. Magn. Reson. Imaging 37, 770-777. doi: 10.1002/jmri.23800

Kapogiannis, D., and Mattson, M. P. (2011). Disrupted energy metabolism and neuronal circuit dysfunction in cognitive impairment and Alzheimer's disease. Lancet Neurol. 10, 187-198. doi: 10.1016/S1474-4422(10)70277-5

Krajcovicova, L., Marecek, R., Mikl, M., and Rektorova, I. (2014). Disruption of resting functional connectivity in Alzheimer's patients and at-risk subjects. Curr. Neurol. Neurosci. Rep. 14, 491. doi: 10.1007/s11910-014-0491-3

La Joie, R., Perrotin, A., De La Sayette, V., Egret, S., Doeuvre, L., Belliard, S., et al. (2013). Hippocampal subfield volumetry in mild cognitive impairment, Alzheimer's disease and semantic dementia. Neuroimage Clin. 3, 155-162. doi: 10.1016/j.nicl.2013.08.007
Landau, S., Harvey, D., Madison, C., Reiman, E., Foster, N., Aisen, P., et al. (2010). Comparing predictors of conversion and decline in mild cognitive impairment. Neurology 75, 230-238. doi: 10.1212/WNL.0b013e3181e8e8b8

Lehmann, M., Koedam, E. L., Barnes, J., Bartlett, J. W., Barkhof, F., Wattjes, M. P., et al. (2013). Visual ratings of atrophy in MCI: prediction of conversion and relationship with CSF biomarkers. Neurobiol. Aging 34, 73-82. doi: 10.1016/j.neurobiolaging.2012.03.010

Leung, K. K., Bartlett, J. W., Barnes, J., Manning, E. N., Ourselin, S., and Fox, N. C. (2013). Cerebral atrophy in mild cognitive impairment and Alzheimer disease: rates and acceleration. Neurology 80, 648-654. doi: 10.1212/WNL.0b013e318281ccd3

Li, Q., Pardoe, H., Lichter, R., Werden, E., Raffelt, A., Cumming, T., et al. (2015). Cortical thickness estimation in longitudinal stroke studies: a comparison of 3 measurement methods. Neuroimage Clin. 8, 526-535. doi: 10.1016/j.nicl.2014.08.017

Li, X., Jiao, J., Shimizu, S., Jibiki, I., Watanabe, K., and Kubota, T. (2012). Correlations between atrophy of the entorhinal cortex and cognitive function in patients with Alzheimer's disease and mild cognitive impairment. Psychiatry Clin. Neurosci. 66, 587-593. doi: 10.1111/pcn.12002

Li, Y. D., Dong, H. B., Xie, G. M., and Zhang, L. J. (2013). Discriminative analysis of mild Alzheimer's disease and normal aging using volume of hippocampal subfields and hippocampal mean diffusivity: an in vivo magnetic resonance imaging study. Am. J. Alzheimers Dis. Other Demen. 28, 627-633. doi: $10.1177 / 1533317513494452$

Liu, X., Tosun, D., Weiner, M. W., Schuff, N., and Alzheimer's Disease Neuroimaging Initiative (2013). Locally linear embedding (LLE) for MRI based Alzheimer's disease classification. Neuroimage 83, 148-157. doi: 10.1016/j.neuroimage.2013.06.033

Liu-Seifert, H., Siemers, E., Holdridge, K. C., Andersen, S. W., Lipkovich, I., Carlson, C., et al. (2015). Delayed-start analysis: mild Alzheimer's disease patients in solanezumab trials, 3.5 years. Alzheimers Dement. 1, 111-121. doi: 10.1016/j.trci.2015.06.006

MacKay, A., Whittall, K., Adler, J., Li, D., Paty, D., and Graeb, D. (1994). In vivo visualization of myelin water in brain by magnetic resonance. Mag. Reson. Med. 31, 673-677. doi: 10.1002/mrm.1910310614

Madden, D. J., Bennett, I. J., Burzynska, A., Potter, G. G., Chen, N. K., and Song, A. W. (2012). Diffusion tensor imaging of cerebral white matter integrity in cognitive aging. Biochim. Biophys. Acta 1822, 386-400. doi: 10.1016/j.bbadis.2011.08.003

Marshall, G. A., Lorius, N., Locascio, J. J., Hyman, B. T., Rentz, D. M., Johnson, K. A., et al. (2014). Regional cortical thinning and cerebrospinal biomarkers predict worsening daily functioning across the Alzheimer's Disease spectrum. J. Alzheimers Dis. 41, 719-728. doi: 10.3233/JAD-132768

Maruszak, A., and Thuret, S. (2014). Why looking at the whole hippocampus is not enough-a critical role for anteroposterior axis, subfield and activation analyses to enhance predictive value of hippocampal changes for Alzheimer's disease diagnosis. Front. Cell. Neurosci. 8:95. doi: 10.3389/fncel.2014.00095

Mazza, M., Marano, G., Traversi, G., Bria, P., and Mazza, S. (2011). Primary cerebral blood flow deficiency and Alzheimer's disease: shadows and lights. J. Alzheimers Dis. 23, 375-389. doi: 10.3233/JAD-2010-090700

McMillan, C. T., Avants, B. B., Cook, P., Ungar, L., Trojanowski, J. Q., and Grossman, M. (2014). The power of neuroimaging biomarkers for screening frontotemporal dementia. Hum. Brain Mapp. 35, 4827-4840. doi: $10.1002 / \mathrm{hbm} .22515$

Murray, M. E., Przybelski, S. A., Lesnick, T. G., Liesinger, A. M., Spychalla, A., Zhang, B., et al. (2014). Early Alzheimer's disease neuropathology detected by proton MR spectroscopy. J. Neurosci. 34, 16247-16255. doi: 10.1523/JNEUROSCI.2027-14.2014

Musiek, E. S., Chen, Y., Korczykowski, M., Saboury, B., Martinez, P. M., Reddin, J. S., et al. (2012). Direct comparison of fluorodeoxyglucose positron emission tomography and arterial spin labeling magnetic resonance imaging in Alzheimer's disease. Alzheimers Dement. 8, 51-59. doi: $10.1016 /$ j.jalz.2011.06.003

Nir, T. M., Jahanshad, N., Villalon-Reina, J. E., Toga, A. W., Jack, C. R., Weiner, M. W., et al. (2013). Effectiveness of regional DTI measures in distinguishing Alzheimer's disease, MCI, and normal aging. Neuroimage Clin. 3, 180-195. doi: 10.1016/j.nicl.2013.07.006 
O’Brien, J. T., Firbank, M. J., Davison, C., Barnett, N., Bamford, C., Donaldson, C., et al. (2014). 18F-FDG PET and Perfusion SPECT in the Diagnosis of Alzheimer and Lewy Body Dementias. J. Nucl. Med. 55, 1959-1965. doi: 10.2967/jnumed.114.143347

Oz, G., Alger, J. R., Barker, P. B., Bartha, R., Bizzi, A., Boesch, C., et al. (2014). Clinical proton MR spectroscopy in central nervous system disorders. Radiology 270, 658-679. doi: 10.1148/radiol.13130531

Palesi, F., Vitali, P., Chiarati, P., Castellazzi, G., Caverzasi, E., Pichiecchio, A., et al. (2012). DTI and MR Volumetry of Hippocampus-PC/PCC Circuit: in search of early micro- and macrostructural signs of Alzheimers's Disease. Neurol Res. Int. 2012:517876. doi: 10.1155/2012/517876

Perl, D. P. (2010). Neuropathology of Alzheimer's disease. Mt. Sinai J. Med. 77, 32-42. doi: $10.1002 / \mathrm{msj} .20157$

Perrotin, A., de Flores, R., Lamberton, F., Poisnel, G., La Joie, R., de la Sayette, V., et al. (2015). Hippocampal subfield volumetry and 3D surface mapping in subjective cognitive decline. J. Alzheimers Dis. 48(Suppl. 1), S141-S150. doi: 10.3233/jad-150087

Peters, R. (2006). Ageing and the brain. Postgrad. Med. J. 82, 84-88. doi: 10.1136/pgmj.2005.036665

Redolfi, A., Manset, D., Barkhof, F., Wahlund, L.-O., Glatard, T., Mangin, J.-F, et al. (2015). Head-to-head comparison of two popular cortical thickness extraction algorithms: a cross-sectional and longitudinal study. PLoS One 10:e117692. doi: 10.1371 /journal.pone. 0117692

Risacher, S. L., Saykin, A. J., West, J. D., Shen, L., Firpi, H. A., and McDonald, B. C. (2009). Baseline MRI predictors of conversion from MCI to probable $\mathrm{AD}$ in the $\mathrm{ADNI}$ cohort. Curr. Alzheimer Res. 6, 347-361. doi: $10.2174 / 156720509788929273$

Salat, D. H., Chen, J. J., van der Kouwe, A. J., Greve, D. N., Fischl, B., and Rosas, H. D. (2011). Hippocampal degeneration is associated with temporal and limbic gray matter/white matter tissue contrast in Alzheimer's disease. Neuroimage 54, 1795-1802. doi: 10.1016/j.neuroimage.2010.10.034

Salat, D. H., Kaye, J. A., and Janowsky, J. S. (1999). Prefrontal gray and white matter volumes in healthy aging and Alzheimer disease. Arch. Neurol. 56, 338-344. doi: 10.1001/archneur.56.3.338

Santillo, A. F., Mårtensson, J., Lindberg, O., Nilsson, M., Manzouri, A., Landqvist Waldö, M., et al. (2013). Diffusion tensor tractography versus volumetric imaging in the diagnosis of behavioral variant frontotemporal dementia. PLoS ONE 8:e66932. doi: 10.1371/journal.pone.0066932

Scahill, R. I., and Fox, N. C. (2007). Longitudinal imaging in dementia. Br. J. Radiol. 80, S92-S98. doi: $10.1259 / \mathrm{bjr} / 78981552$

Schöll, M., Samuel Lockhart, N., Daniel Schonhaut, R., James O’Neil, P., Janabi, M., Ossenkoppele, R., et al. (2016). PET imaging of Tau Deposition in the aging human brain. Neuron 89, 971-982. doi: 10.1016/j.neuron.2016.01.028

Schuff, N., Tosun, D., Insel, P. S., Chiang, G. C., Truran, D., Aisen, P. S., et al. (2012). Nonlinear time course of brain volume loss in cognitively normal and impaired elders. Neurobiol. Aging 33, 845-855. doi: 10.1016/j.neurobiolaging.2010.07.012

Schuff, N., Woerner, N., Boreta, L., Kornfield, T., Shaw, L. M., Trojanowski, J. Q., et al. (2009). MRI of hippocampal volume loss in early Alzheimer's disease in relation to ApoE genotype and biomarkers. Brain 132, 1067-1077. doi: 10.1093/brain/awp007

Selnes, P., Aarsland, D., Bjornerud, A., Gjerstad, L., Wallin, A., Hessen, E., et al. (2013). Diffusion tensor imaging surpasses cerebrospinal fluid as predictor of cognitive decline and medial temporal lobe atrophy in subjective cognitive impairment and mild cognitive impairment. J. Alzheimers Dis. 33, 723-736. doi: 10.3233/JAD-2012-121603

Sexton, C. E., Kalu, U. G., Filippini, N., Mackay, C. E., and Ebmeier, K. P. (2011). A meta-analysis of diffusion tensor imaging in mild cognitive impairment and Alzheimer's disease. Neurobiol. Aging 32, 2322.e5-18. doi: 10.1016/j.neurobiolaging.2010.05.019

Sheline, Y. I., and Raichle, M. E. (2013). Resting state functional connectivity in preclinical Alzheimer's disease. Biol. Psychiatry 74, 340-347. doi: 10.1016/j.biopsych.2012.11.028

Shu, N., Wang, Z., Qi, Z., Li, K., and He, Y. (2011). Multiple diffusion indices reveals white matter degeneration in Alzheimer's disease and mild cognitive impairment: a tract-based spatial statistics study. J. Alzheimers Dis. 26(Suppl. 3), 275-285. doi: 10.3233/JAD-2011-0024
Silbert, L., Quinn, J., Moore, M., Corbridge, E., Ball, M., Murdoch, G., et al. (2003). Changes in premorbid brain volume predict Alzheimer's disease pathology. Neurology 61, 487-492. doi: 10.1212/01.WNL.0000079053.77227.14

Small, G. W., Kepe, V., Ercoli, L. M., Siddarth, P., Bookheimer, S. Y., Miller, K. J., et al. (2006). PET of brain amyloid and Tau in mild cognitive impairment. $N$. Engl. J. Med. 355, 2652-2663. doi: 10.1056/NEJMoa054625

Sotiropoulos, S. N., Jbabdi, S., Xu, J., Andersson, J. L., Moeller, S., Auerbach, E. J., et al. (2013). Advances in diffusion MRI acquisition and processing in the Human Connectome Project. Neuroimage 80, 125-143. doi: 10.1016/j.neuroimage.2013.05.057

Sperling, R. A., Jack, C. R. Jr., Black, S. E., Frosch, M. P., Greenberg, S. M., Hyman, B. T., et al. (2011). Amyloid-related imaging abnormalities in amyloid-modifying therapeutic trials: recommendations from the Alzheimer's Association Research Roundtable Workgroup. Alzheimers Dement. 7, 367-385. doi: 10.1016/j.jalz.2011.05.2351

Stebbins, G. T., and Murphy, C. M. (2009). Diffusion tensor imaging in Alzheimer's disease and mild cognitive impairment. Behav. Neurol. 21, 39-49. doi: $10.1155 / 2009 / 915041$

Sullivan, E. V., Marsh, L., Mathalon, D. H., Lim, K. O., and Pfefferbaum, A. (1995). Age-related decline in MRI volumes of temporal lobe gray matter but not hippocampus. Neurobiol. Aging 16, 591-606. doi: 10.1016/01974580(95)00074-O

Thompson, P. M., Hayashi, K. M., de Zubicaray, G. I., Janke, A. L., Rose, S. E., Semple, J., et al. (2004). Mapping hippocampal and ventricular change in Alzheimer disease. Neuroimage 22, 1754-1766. doi: 10.1016/j.neuroimage.2004.03.040

Tumati, S., Martens, S., and Aleman, A. (2013). Magnetic resonance spectroscopy in mild cognitive impairment: systematic review and meta-analysis. Neurosci. Biobehav. Rev. 37, 2571-2586. doi: 10.1016/j.neubiorev.2013.08.004

Tzourio-Mazoyer, N., Landeau, B., Papathanassiou, D., Crivello, F., Etard, O., Delcroix, N., et al. (2002). Automated anatomical labeling of activations in SPM using a macroscopic anatomical parcellation of the MNI MRI single-subject brain. Neuroimage 15, 273-289. doi: 10.1006/nimg.2001.0978

Van Hoesen, G. W., Hyman, B. T., and Damasio, A. R. (1991). Entorhinal cortex pathology in Alzheimer's disease. Hippocampus 1, 1-8. doi: 10.1002/hipo.450010102

Vandenberghe, R., Adamczuk, K., Dupont, P., Laere, K. V., and Chételat, G. (2013). Amyloid PET in clinical practice: its place in the multidimensional space of Alzheimer's disease. Neuroimage Clin. 2, 497-511. doi: 10.1016/j.nicl.2013.03.014

Wang, H., Tan, L., Wang, H. F., Liu, Y., Yin, R. H., Wang, W. Y., et al. (2015). Magnetic resonance spectroscopy in Alzheimer's Disease: systematic review and meta-analysis. J. Alzheimers Dis. 46, 1049-1070. doi: 10.3233/JAD-143225

Wang, L., Swank, J. S., Glick, I. E., Gado, M. H., Miller, M. I., Morris, J. C., et al. (2003). Changes in hippocampal volume and shape across time distinguish dementia of the Alzheimer type from healthy aging. Neuroimage 20, 667-682. doi: 10.1016/S1053-8119(03)00361-6

Ward, A., Tardiff, S., Dye, C., and Arrighi, H. M. (2013). Rate of conversion from prodromal Alzheimer's disease to Alzheimer's dementia: a systematic review of the literature. Dement. Geriatr. Cogn. Dis. Extra 3, 320-332. doi: $10.1159 / 000354370$

Weiner, M. W., Veitch, D. P., Aisen, P. S., Beckett, L. A., Cairns, N. J., Cedarbaum, J., et al. (2015). 2014 Update of the Alzheimer's Disease neuroimaging initiative: a review of papers published since its inception. Alzheimers Dement. 11, e1-e120. doi: 10.1016/j.jalz.2014.11.001

Westlye, L. T., Walhovd, K. B., Dale, A. M., Espeseth, T., Reinvang, I., Raz, N., et al. (2009). Increased sensitivity to effects of normal aging and Alzheimer's disease on cortical thickness by adjustment for local variability in gray/white contrast: a multi-sample MRI study. Neuroimage 47, 1545-1557. doi: 10.1016/j.neuroimage.2009.05.084

Whitwell, J. L., Dickson, D. W., Murray, M. E., Weigand, S. D., Tosakulwong, N., Senjem, M. L., et al. (2012). Neuroimaging correlates of pathologically defined subtypes of Alzheimer's disease: a case-control study. Lancet Neurol. 11, 868-877. doi: 10.1016/S1474-4422(12)70200-4

Wierenga, C. E., Hays, C. C., and Zlatar, Z. Z. (2014). Cerebral blood flow measured by arterial spin labeling MRI as a preclinical marker of Alzheimer's disease. J. Alzheimers Dis. 42(Suppl. 4), S411-S419. doi: 10.3233/JAD-141467 
Wolk, D. A., and Detre, J. A. (2012). Arterial spin labeling MRI: an emerging biomarker for Alzheimer's disease and other neurodegenerative conditions. Curr. Opin. Neurol. 25, 421-428. doi: 10.1097/WCO.0b013e328354ff0a

Wood, B., Knight, M. J., Tsivos, D., Oliver, R., Coulthard, E., and Kauppinen, R. A. (2015). Magnetic resonance scanning and image segmentation procedure at 3 $\mathrm{T}$ for volumetry of human hippocampal subfields. Biomed. Spectrosc. Imaging 4, 197-208. doi: 10.3233/BSI-150109

Yang, J., Pan, P., Song, W., Huang, R., Li, J., Chen, K., et al. (2012). Voxelwise metaanalysis of gray matter anomalies in Alzheimer's disease and mild cognitive impairment using anatomic likelihood estimation. J. Neurol. Sci. 316, 21-29. doi: 10.1016/j.jns.2012.02.010

Yushkevich, P. A., Amaral, R. S., Augustinack, J. C., Bender, A. R., Bernstein, J. D., Boccardi, M., et al. (2015). Quantitative comparison of 21 protocols for labeling hippocampal subfields and parahippocampal subregions in in vivo MRI: towards a harmonized segmentation protocol. Neuroimage 111, 526-541. doi: 10.1016/j.neuroimage.2015.01.004

Zhang, B., Ferman, T. J., Boeve, B. F., Smith, G. E., Maroney-Smith, M., Spychalla, A. J., et al. (2015). MRS in mild cognitive impairment: early differentiation of dementia with Lewy bodies and Alzheimer's disease. J. Neuroimaging 25, 269-274. doi: 10.1111/jon.12138
Zhang, B., Xu, Y., Zhu, B., and Kantarci, K. (2014). The role of diffusion tensor imaging in detecting microstructural changes in prodromal Alzheimer's disease. CNS Neurosci. Ther. 20, 3-9. doi: 10.1111/cns. 12166

Zhou, J., and Seeley, W. W. (2014). Network dysfunction in Alzheimer's disease and frontotemporal dementia: implications for psychiatry. Biol. Psychiatry 75, 565-573. doi: 10.1016/j.biopsych.2014. 01.020

Conflict of Interest Statement: The authors declare that the research was conducted in the absence of any commercial or financial relationships that could be construed as a potential conflict of interest.

Copyright (c) 2016 Knight, McCann, Kauppinen and Coulthard. This is an openaccess article distributed under the terms of the Creative Commons Attribution License (CC BY). The use, distribution or reproduction in other forums is permitted, provided the original author(s) or licensor are credited and that the original publication in this journal is cited, in accordance with accepted academic practice. No use, distribution or reproduction is permitted which does not comply with these terms. 